\title{
Pop-Up Store Adoption by Brands
}

\author{
Ghalia BOUSTANI* \\ Paris 1 Panthéon Sorbonne, France
}

*Corresponding author: Ghalia BOUSTANI, Department of UFR06, Paris 1 Panthéon

Sorbonne, France.

Received Date: January 21, 2021

Published Date: February 19, 2021

\begin{abstract}
Ephemeral stores have several features that appeal to consumers and brands; to the former, they present an innovative and exciting concept and to the latter, they are agile tools helping brands meet specific objectives. Previous research developed on the subject has focused on studying pop-up stores in the North American and European markets. Following a qualitative study, the objective of this research was the understanding of the reasons for the adoption of ephemeral stores by Lebanese brands. The study's results highlighted specific features related to the adoption of Lebanese pop-up stores; these formats can be testing or experimentation tools. Pop-up stores can also serve to mover merchandise or communicate brand novelties. Finally, in the Lebanese context, pop-up stores can trigger customer surprise or reinforce the brands' social dimension. The current research findings join the results of previously published studies.
\end{abstract}

Keywords: Ephemeral stores; Pop-up stores; Ephemeral retailing

\section{Introduction}

So far, academic literature has focused on studying traditional or virtual stores rather than ephemeral stores. Nevertheless, some research which has been particularly interested in these retail outlets underlines important features that these stores have and their resemblance to experiential stores. These "temporary", "ephemeral" or transitory stores call for a new initiative that merits our attention.

Many brands have been recently adopting ephemeral stores; whether to open up a seasonal retail store, an ephemeral bar, a pop-up restaurant, an interactive kiosk or a hangar by the sea, retail brands are adopting formats that best meet with their needs and that could relate best to the target audience [1]. Albeit the conception and application's facility of ephemeral stores, today's market competitiveness makes it difficult for entrepreneurial brands to stand out facing retail giants if their concepts were not innovative.

The brand ideas behind their ephemeral store projects are to offer customers new environments in which they can immerse and through which they can come closer to them [2]. There are different motives to the adoption of these stores by brands; to name a few, ephemeral stores are communication tools helping the brand reveal ideas, concepts or product lines. They also help the brand sell product lines or exclusive lines within a short period. Unlike other marketing and communication tools, ephemeral stores allow brands to collect insights about their customers and from their customers instantly. Despite their success, ephemeral store adoptions remained mainly in North America and Europe up until the years $2013[3,4]$.

\section{What Is Meant By « Ephemeral Stores »?}

Also known as "pop-up stores", ephemeral stores are platforms that interest both consumers and brands. They have several particularities which make them attractive and which differentiate them from traditional points of sale. Brands find the concept interesting and fit well into their strategies. Indeed, "even if pop-up stores cannot last for long, they are here to stay" [5,6].

The short lifespan of pop-up stores and the imprecision of their installation time on the market make them attractive (Shopify, n.d.). This limited lifespan creates urgency for the consumer, and he 
will be motivated by the fact that it is uncertain to find the pop-up store, or the offer presented before it disappears. This fact has been explained by interpretations like "here to-day; gone tomorrow, or "now you see it; now you don't" [7].

Pop-up stores are transportable distribution concepts [8] which give "flavor" to the retail environment; they operate as a magnet attracting those who are likely to be charmed by the brand's innovations (Shopify, n.d.). Pop-up stores are also described as communication tools conveying the brand's promise, its history or its message [8]. Several brands take advantage of these stores to test their products or concepts, knowing that they will not be "judged" if they fail [5].

A great advantage of pop-up stores is the fact that they can be easily assembled or disassembled $[9,10]$ admitting a new unconventional form, inexpensive, and allowing brands to avoid overhead costs and rental costs [11]. Besides, they can transform abandoned places or spaces into attractive spaces by giving them a new meaning, even a new expression. The appearance of ephemeral stores makes places more attractive, thus bringing more traffic or flows of consumers and/or passengers [12]. Pop-up stores take advantage of seasonality and events; they take advantage of it when the consumer is most vulnerable to take a (positive) action towards buying, tasting, visiting, experimenting at the expense.

By building the pop-up store space, the brand informs, educates or gives visitors a chance to discover the space. It is committed to offering the consumer a unique experience in a physical environment while creating an immersive consumption experience. The concept of pop-up stores is linked very closely to experience or a form of experiential marketing [13].

The disadvantages, on the other hand, show that this type of point of sale cannot necessarily support the success of the brand because of its short duration [14,15]. Also, the impact of pop-up stores can disappear if the concept lasts a long time or if the same concept is repeated several times. Consequently, the brand requires a permanent renewal of the themes that will reflect the pop-up stores presented [16]. It is important to consider the installations necessary for assembly and operation within the ephemeral store. Finally, it is not always easy to find an ideal location for the ephemeral store and the negotiation to secure the premises at affordable prices is also a questionable point [17].

\section{Ephemeral Store Characteristics}

A successful pop-up store presents the unique product or service at the optimal price, adapts it to the location and offers a fun experience (Retailtouchpoints, nd): it is characterized by its ability to reflect the brand's identity to the target customers in a given location and for a limited period.

The characteristics of the space include accessibility, interior design and identity. This logic corresponds to the characterization of physical stores, however, rethought from a point of view corresponding to pop-up stores. The view from the outside seeks to make it visible. If the pop-up store uses space comparable to a traditional store, it must present the same logic and the same criteria as traditional stores. The identity of the pop-up store can only be enhanced by the presentation of an "unforgettable" theme [18].

We evaluate a pop-up store by the choice of location. Neglected places or abandoned places like train or metro stations, theaters or castles, or urban places are examples of places where a brand cries to place its pop-up store. In context, a place can be reinvented or created; there are therefore new uses for empty or abandoned spaces $[5,12]$ (examples of the places created are Souk el Akel in Beirut and BOXPARK in London) [19] (Daily Star, 2015). The location is a criterion that helps brands strengthen their reputations [12].

Pop-up stores are positioned between the virtual and the traditional: they materialize the concepts of virtual brands through physical representations on the one hand and build links be-tween traditional representations and digital commerce on the other [20].

Consumers believe that pop-up stores offer novelty and uniqueness. Also, they consider them as a place to test or a place where they can have a unique experience [21]. As for brands, they will have the power to engage directly with the visitor or the consumer through pop-up stores, to deliver them a unique experience [22].

\section{Research Questions}

Up till now, the study of pop-up stores has focused on the North American and /or European markets. They were able to contextualize these types of stores under the approach of experiential marketing. Studies have shown that they are a source of animation and surprise and that they stimulate new purchasing motivations. Following the direct contact between the brand and the consumer in pop-up stores, a multi-sensory experience is presented which will subsequently generate a generation of income, thus merging communication, experience and sale.

Very few studies have paid interest in the Middle Eastern Market and brand adoption of ephemeral stores in this market and particularly in Lebanon. This research seeks to understand the reasons for ephemeral store adoption by Lebanese brands and the motives behind this adoption. Thus, our study enquires the following questions: how are the ephemeral stores operating on the Lebanese market, how do they resemble or differ from the characterizations proposed in existing academic literature and what are the reasons for which the Lebanese brands adopt pop-up stores?

\section{Methodology}

Using semi-structured interviews [23], we collected qualitative data to better understand the motivations of respondents towards pop-up stores in Lebanon [24]. 
The sample's composition is relatively heterogeneous in terms of respondents ( 3 men, 10 women) and brands (15 brands in total; local and international; developing or well developed). We stopped our collection when the responses had reached the semantic saturation threshold and subsequently began to report less novelty to the responses obtained. All the interviews managed during the period of November and December 2015 and January 2016 were recorded and transcribed in full.

All the content of the interview was integrally transcribed, and each interview labelled with information related to the brand, industry, date of the interview and the total time of the interview. Following a vertical and horizontal content analysis, we purified the transcribed texts and we extracted reoccurring verbatim. Then the construction of a "frequency of appearance" grid allowed us to collect the items that appear most by the majority of respondents.

\section{Results}

Qualitative data analysis reveals results representing the specificities and characteristics of the ephemeral stores operating on the Lebanese market according to the developed brands and the brands under development. A clear separation of discourse is highlighted when it comes to brands fitting in either/or categorization. In the case of developed brands, the adoption of pop-up stores follows a clear strategy and expects specific results from its project. As for developing brands, pop-up stores are a means of gaining access to a market, building an address book or improving visibility while hoping to sell the collections on offer. For Lebanese brands, a pop-up store is:

A test and experimentation tool: Lebanese brand managers can test the market using ephemeral stores. These types of stores are means of testing and exploring a distribution channel envisaged by the brand or they can help in testing brand concepts or brand products/collections. In the former case, brands that operated through seasonal markets or kiosks and looking to explore a traditional distribution channel, such as a boutique, profited from ephemeral stores to test whether the brand's identity could be transposed onto the desired format and whether the brand has the capability of operationalizing its supply and teams to meet with the standards if the desired format. In the latter, Lebanese brands adopt ephemeral stores to test new concept or collections and get the reactions from their customers, convinced that customers "tend to forget" and "be less judgmental" after visiting the ephemeral store as, in case of failure, the brand will refrain from repeating it.

A strategy of movement of goods: According to Lebanese brand's distribution strategy, an ephemeral store can be a means of helping the brands to liquidate or sell their products. How-ever, the sale of products must not be confused with destocking operations; an ephemeral store represents an opportunity and a possibility to present exclusive and limited products for a limited time and a targeted clientele. The ephemeral store's appearance during a particular time or seasonal event was an opportunity to present limited edition collections with limited stocks that privileged customers could get hold of during the time of the event. In other cases, developing brands seized the opportunity of appearing in ephemeral stores to propose their collections to audiences that they haven't been able to reach beforehand.

A trigger for surprises: Time is a key element in the design of ephemeral stores. Lebanese brands take advantage of the brief appearance to trigger instant actions, such as product proposals or promotional offers, accompanied by the creation of the surprise effect. Brand man-agers are also aware of the power of ephemeral store's surprise effect on consumers; "surprised" consumers will have a positive reaction towards the brand that can engender engagement, purchase or other actions. Most importantly, when the surprise effect is positive and strong, customers will generate a positive buzz and positive word-of-mouth regarding the "happening".

A communication tool: Lebanese brands want to focus their efforts to communicate ephemeral stores through social networks and to communicate at the location of the event. Social media communications seem to be indissociable from the ephemeral store formula on the Lebanese market. Intense communications on social networks share information about the brand and tease customers before the announced date. What is remarkable though is the communications taking place "during" the event. Lebanese brand managers intensify information sharing, photo sharing and encourage customers to "post, share and tag" comments and pictures about their experience during their visit or regarding their purchases. Lebanese brand managers also consider that the brief appearance of an ephemeral store is "in itself a means of communication", and this is a rare tool that they are keen on investing in regularly.

A learning tool: When it adopts an ephemeral store, a brand is convinced that it can test or try out without being judged; this applies to the case of developing or developed brands. Lebanese brands believe that ephemeral stores are "possibilities" allowing them to present different and unique concepts during the limited periods to have a clearer judgement and decision-making. In times of market instabilities, ephemeral stores give Lebanese brands a clearer view of the market and a firmer action plan with regards to their brands. This type of store is perceived as a learning tool as it can be constantly repeated, does attract curious customers at all times and thus a constant information-acquisition terrain.

A connecting link: An ephemeral store is a social event that puts the Lebanese brand in direct contact with consumers and consumers with each other. The particularities of this "happening" are the exchange, sharing, and direct feedback that the brand can preciously collect and analyze. Brand managers and brand personnel constitute an integral part of the ephemeral store through its life cycle as they are constantly present to represent the brand and stand ready for the consumer who is visiting. The 
human and interactive variable plays an important role in the success of Lebanese ephemeral stores; for consumers, discovering an ephemeral store does not only relate to an access to the brand's offering but rather, it is a recreational activity allowing the customer to discover, meet, exchange with others, and have a nice time.

\section{Discussion}

The usefulness of ephemeral stores differs according to the brand's offering type and its life cycle stage. For Lebanese developing brands, an ephemeral store is a satisfying format sup-porting the facts that the brand hasn't been able to launch properly on the market. It is a creative platform communicating the brand and the products sold and which presents the products to facilitate their sale. An ephemeral store, therefore, gives the brand the possibility of expanding its presentation perimeter and providing it with more visibility. While listening to consumers, the brand can further test its concept and product lines. The developing brand will be able to reach a positioning that is more suited to its targeted clientele.

For developed Lebanese brands, an ephemeral store aligns with the brand's distribution and communication strategies. It acts as a brand communication medium or is used as a sales or stock-sales tool. Developed brands invest in ephemeral stores to advance a unique experience while encouraging curious consumers to come and discover and exchange ideas.

The ephemeral store shortens the distance between design and sale. It triggers action at the right time, in the right environment, with the right crowd and results in an immersive experience. It helps promote the brand in a location outside of its distribution area, spreading the message it wanted to communicate through word of mouth.

To conclude, an ephemeral store is considered as a flexible tool allowing the brand (whether developing or developed to have more freedom in terms of choice of conceptualization, the proposal of the range of products/offering and choice of places of appearance. It is also a great tool to collect valuable information that can help in taking a decision based on "real-time" data. Lebanese ephemeral stores are adopted by brands for they provide them with flexible solutions and helping them figure out the better choices to meet their customer needs.

The results of the qualitative study find elements in common with advanced studies on the subject. An ephemeral store is a source of excitement and curiosity [25] and speaks to those looking for novel and innovative retail concept. Ephemeral stores aesthetically manifest themselves allowing customers/visitors the opportunity to make discoveries, experiment, test or to try products, to enjoy the entertainment presented by the brand [26] and to live a unique experience [13]. Lebanese brand managers have highlighted the importance of putting forward concepts that appeal to customers and engage them.
Likewise, our study joins the results of previous studies showing that pop-up stores merge communication and sales in a given place and during a limited-term lifespan [25,27] An ephemeral store is a brand happening and helps in creating awareness or realizing instant sales of products or limited collections. Lebanese brands have described consumers as "curious" and "enthusiastic". However, Lebanese brand managers express less interest in personal, psychological or socio-demographic characteristics of consumers as presented in previous research $[25,26]$.

\section{Research Limits and Future Research Avenues}

The results of our research have highlighted some characteristics relating to the application of pop-up stores in the Lebanese market, especially according to developing brands and developed brands. If the conclusions to which we approach must be put into perspective given the qualitative nature of our study, the fact remains that they can teach future research in the study of different types of ephemeral stores. As the spread of the popup store is still timid on the Lebanese market, few brands have engaged in these types of points of sale. A more varied sample of brands can enrich the results of research aimed at understanding the motivation of Lebanese brands to adopt pop-up stores.

A future avenue of research could envisage a comparative study of developing and developed brands to underline the differences between their strategies and objectives, the differences between their atmospheric designs or budget allocations for conceptualization, their product ranges offered and their communications. As the use of ephemeral stores becomes more common on the Lebanese market, it would be worthy of focusing in research to understand consumer's attitudes towards these types of stores.

\section{Conclusions and Implications}

The adoption of pop-up stores by Lebanese brands highlights specific features of the Middle East markets which join those of the North American and European markets on the one hand and presents points of difference on the other. The interest of our study is that it contributes to the enrichment of the literature on pop-up stores by highlighting specific features of the Middle East market. Lebanese brand managers are invited to prioritize their expectations concerning setting up pop-up stores. It is very important to select the strategic direction expected from a popup store for a developed brand or a developing brand; be it sales, communication, awareness, being there in the right place at the right time.

Lebanese brand managers are invited to set clear strategies and objectives from their ephemeral stores; they should also make sure that their brand's identity is always reflected in the ephemeral store's design and execution, as having recurrent ephemeral stores with varied concepts might deviate the brand from its original identity if not done properly. This being pro-posed, a thorough understanding 
of the consumer to whom the brand wishes to address is a priority; this data will help to better design, communicate and manage the ephemeral store on the Lebanese market. As customers have an important say in today's brand offering, managers should be keen on collecting all insights concerning their desires and aspirations.

Omnichannel retailing becomes an important lever for brands wishing to support themselves in the market with fierce competitive brands. If the ephemeral store is one of the different brand distribution channels, then managers are encouraged to ensure a smooth transition between these channels. Of course, Lebanese brand managers are to prioritize what should be proposed in each channel in terms of access to information, access to products or attribution of power or control to consumers. Having an omnichannel direction, brand managers are invited to invest in making the transition between all touchpoints flawless and "seamless".

Lebanese ephemeral stores are opportunities for meetings between the brand (developed or developing) and the consumer as well as meeting opportunities for consumers and their peers. Brand managers are therefore invited to enhance the social dimension of their ephemeral store's atmosphere and to support events that "humanize" the exchange relationship between brand and consumer. Today's shopping motives go beyond a mere acquisition of merchandise and customers look for more experience and expressions throughout their retail trips. This merits the Lebanese brand's close attention.

We strongly recommend that Lebanese brand managers communicate their ephemeral stores correctly so that they can reach the targeted clientele and transmit the right information on the digital platforms so they can bring Internet users/consumers back to the ephemeral store. In the case of several distribution channels, communications channels help customers move freely between different channels and deciding when and what to get in touch with the brand. Lebanese brands' investment in communications along their ephemeral stores will help in creating physical proximity between the brand and the consumer.

\section{Acknowledgement}

None.

\section{Conflict of Interest}

Author declare no conflict of interest.

\section{References}

1. Jiang (2017) Has the Pop-Up Shop Bubble Popped?

2. Sim (2018) Why luxury fashion brands are leveraging pop-up concept stores.

3. Baras J (2015) What's 'In Store' for the Pop-Up Industry in 2015, in Independent Retailer.

4. Khotari M (2014) Pop-up store is concept whose time has come.

5. Dean W ( 2012) independent.co.uk.

6. Sherman L (2008) Forbes.

7. Economist (2009) Gone tomorrow.

8. Losif R (2015) https://viuz.com/2015/10/29/le-phenomene-des-popup-stores-parti-pour-durer/?trk=pulse-det-art_view_ext.

9. Hallisy B (2006) Taking it to the streets: steps to an effective- and ethical- guerilla marketing campaign. Public Relations Tactics 13(3): 1-13.

10. Ryan J (2008) Retail Week.

11. Carapiet L (2009) Pop-up shops quite the fashion.

12. Horne M (2014) Temporary use of pop-up environment's potential for repurposing neglected buildings and spaces. Georgia State University, USA.

13. Holmgren A, Olofsson S (2015) Pop-up stores: The attraction of ephemeral experiences.

14. Anon, n.d (2016) NiBusinessInfo.co.uk.

15. Anon, n.d. (2016) Shopify shops/marketing-your-pop-up-pt-1.

16. Firestone BM (2006) Here today, Gone tomorrow!

17. Tomlinson M (2014) [Online] www.business.ee.co.uk

18. Gibbs A (2015) http://www.cnbc.com/2015/08/21/f-the-pop-upbusiness.

19. Daily Star (2015) www.dailystar.com/Life/Lubnan.

20. Shopify (2016) Shopify.com/guides/WhyRunAPopUp.

21. (2011) Norentoffice.

22. Sabiote E, Ballester M (2011) Marcas de experiencia: marcando la diferencia. Estudios generales, Octubre-Diciembre 27(121): 59-77.

23. Lunardo R, Saintives C, Roux D (2012) Une étude exploratoire des inférences de contrôle du consommateur face à l'atmosphère du point de vente. Management et Avenir 55: 55-78.

24. Frisch F (1999) Les études qualitatives. Éditions d'organisation ed. s.l.Eyerolls.

25. Picot-Coupey K (2014) The pop-up store as a foreign operation mode (FOM) for retailers. International Journal of Retail \& Distribution Management 42(7): 643-670

26. Influencia (2015) Le consommateur en manque de popup stores.

27. Filser M (2008) L'expérience de consommation : Concepts, modèles et enjeux managériaux. Recherche et Applications en Marketing. Marketing Expérientiel 23(3): 1-4. 